\title{
EDITORIAL
}

\section{Microbiology Education in Nepal}

Microbiology education in bachelor level was started in Nepal since 1978 from Tri-chandra campus. Master's in Microbiology was started since 1990 from Central Department of Microbiology, Tribhuvan University. Now, M.Sc. programme has been expanded to three constituents and eight affiliated campuses of Tribhuvan University. Since 2012, M.Sc. Microbiology programme has been changed into semester system from annual system.

The curriculum of microbiology is always designed to upgrade B.Sc. and M.Sc. Microbiology degree of Institute of Science and Technology, Tribhuvan University to international level in accordance to latest advances in microbiology. The curriculum emphasizes on professional as well as research based teaching learning practice. The curriculum has aimed to produce qualified microbiologists, molecular biologists, researchers and scientists as per national and international demand. Bachelor of Science in Microbiology emphasizes to produce students with fundamental knowledge and practical skills of microbiology, microbiology related subjects including biochemistry, microbial biotechnology, and applied subjects of microbiology including agriculture and food microbiology, public health and medical microbiology. Bachelor degree holders are also learned to conduct microbiology research and report writing independently or in group. The master's degree holders are able to use skills of modern molecular biology techniques in basic science research or in applied research areas of Microbiology. The graduates are able to work as a qualified scientist for investigating the potential uses of microorganisms to produce antibiotics, antibodies, steroids, vaccines, hormones and other products of microbial origin. The Master's degree holders are able to work as a professional microbiologist and research scientist in the laboratories for monitoring the diagnostic tests, identifying the causative agents of infectious diseases and helping to control those infectious diseases. They are able to work as qualified professionals and researchers in the institutions related to food production, food quality control, crop protection and soil fertility. The Master's degree holders are eligible to be the lecturers of Microbiology programme offered by Institute of Science and Technology and other institutions of Tribhuvan University or other universities for teaching, mentoring and supervising bachelors and masters level microbiology students. Microbiologists from Nepal are always in position to contribute to the science and service to the nation.

\section{Dr. Megha Raj Banjara, Associate Professor}

Chief Editor

Tribhuvan University Journal of Microbiology (TUJM) 